\title{
Combustion Characteristics and Cyclic Irregularity of an EFI Gasoline Engine Fuelled with n-Butanol/Gasoline Blends
}

\author{
Zhiyuan. Hu* ${ }^{1}$, Yan. Qin ${ }^{2}$, Piqiang. Tan ${ }^{3}$, Diming. Lou ${ }^{4}$ \\ School of Automotive Studies, Tongji University, Shanghai 201804, China \\ E-mail: ${ }^{1}$ huzhiyuan@tongji.edu.cn, ${ }^{2}$ qinyanbad@ 163.com, ${ }^{3}$ tpq2000@ 163.com, ${ }^{4}$ loudiming@
}

\begin{abstract}
An experimental study was conducted to evaluate the combustion characteristics of blends of $\mathrm{n}$-butanol to gasoline with volume ratios of $0 \%, 20 \%, 50 \%$, and $85 \%$ in addition to neat n-butanol on an electronic fuel injection (EFI) gasoline engine. Without any modifications to the original engine, the tests were carried out using the above five test fuels, with the engine working at maximum torque speed (3000 rpm) and four loads $(25 \%, 50 \%, 75 \%$ and $100 \%$ of the maximum torque). The combustion characteristics including cylinder pressure, instantaneous and cumulative heat release were analysed. The test results show that all the peak values of cylinder pressure (CP), pressure rise rate (PRR), instantaneous heat release rate (IHRR) as well as total heat release of $n$-butanol/gasoline blends are lower than those of gasoline, and the higher the percentage of n-butanol is, the larger the reduction becomes. The crank angles of the peak values of CP, PRR and IHRR are larger than those of gasoline, whereas the crank angle of the total heat release is smaller than that of gasoline. The cyclic irregularity of $n$-butanol/gasoline bends is higher than that of gasoline. Therefore, the combustion of n-butanol/gasoline blends becomes mild, which further gives the benefit of reducing $\mathrm{NO}_{\mathrm{X}}$ emissions. However, the spark timing of the prototype should be advanced more in order to avoid power decreasing of n-butanol /gasoline blends.
\end{abstract}

Keywords: EFI gasoline engine; combustion characteristics; cyclic irregularity; $n$-butanol, blends.

\section{Introduction}

With high growth of vehicle amounts, automobile industry is faced with severe challenges to reduce its fuel consumption and pollutant emissions together with $\mathrm{CO}_{2}$ emissions. Among all of the possible solutions, one popular and effective way is to develop clean alternative fuels for automobiles. Recently, considerable attention has been paid to bio-fuel, which processes the added advantages of being renewable. Especially, bio-butanol has proved to be a very promising bio-fuel with the ability to completely replace or partially substitute for both gasoline and diesel [1]. Zeng et al. [2] introduced the favourable properties of butanol (nbutanol and iso-butanol) as vehicle alternative fuel: widespread sources, high energy content, high boiling point, high octane number, low vapour pressure as well as low corrosiveness. Moreover, Wigg [3] indicated that butanol has the advantages of good solubility in gasoline and reliable safety of transport in his study on emissions of butanol using a spark ignition (SI) engine.

The combustion characteristics of fuel are the most important indexes to evaluate its combustion process in the cylinder chamber, and closely related to thermal efficiency, fuel economy, and emissions of the engine. Therefore, many literatures have paid attention to study the combustion characteristics of butanol. Serras-Pereira et al. [4], who studied characteristics of ethanol, butanol, isooctane and gasoline sprays and combustion in a directinjection(DI) SI engine, showed that the shapes of the spray of butanol are little influenced by temperature of cooling water, and the way the flame of butanol spreads is similar to that of gasoline. The work did by Merola et al. [5], investigating the effect of n-butanol content in nbutanol/gasoline blends (hereafter called n-butanol blends) on the combustion process, showed that n-butanol blends with n-butanol concentration of $20 \%$ allow engine working in more advanced spark timing without occurrence of abnormal combustion. By analysing the heat release of butanol/gasoline blends (hereafter called butanol blends), Yang et al. [6] found that, without any modifications to the original engine, the ignition delay of butanol blends is longer than that of gasoline, while the peak value of IHRR of butanol blends is smaller. What's more, literatures [7-9] discovered that when the blend ratio of butanol is less than $20 \%$, the engine power remains about the same, while CO and $\mathrm{NO}_{\mathrm{X}}$ emissions decrease.

The test engine used for this study is an electronic fuel injection (EFI) gasoline engine, and researches on combustion characteristics of blends fuel of n-butanol to China IV gasoline with volume ratios of $0 \%, 20 \%, 50 \%$ and $85 \%$ in addition to neat n-butanol were carried out, respectively. In this experiment, cylinder pressure (CP), pressure rise rate (PRR), instantaneous heat release rate (IHRR) and cumulative fraction of heat release (CFHR) of the test engine fuelled with $\mathrm{n}$-butanol blends were analysed.

\section{Experimental Setup and Method \\ 2.1 Experimental Engine and Setup}

The test engine is an in-line, four-cylinder, four-stroke, naturally aspirated, water cooled EFI gasoline engine. Engine specifications are listed in Table 1.

The experimental setup included an AVL engine test bench, DEWE-5000 combustion analyser, Kistler crank angle signal generator, etc. The accuracies of torque and crank angle of the test bench were $\pm 0.3 \%$ and $\pm 1 \%$, respectively. The cylinder pressure was measured with a Kistler model 6117BFD17 piezoelectric pressure transducer (measuring range: 0 150 bar; sensitivity: $-16.24 \mathrm{pC} / \mathrm{bar}$; linearity $\leq \pm 0.1 \%$ FSO), which was integrated within a spark plug on the first cylinder head and connected to a 
Kister 5011A model charge amplifier. The charge amplifier was used to produce an output voltage which was then converted to digital signals and finally recorded by combustion analyser.

Test fuels are China IV gasoline (G100) (equal to European IV gasoline), neat n-butanol (Bu100), and blends of n-butanol to gasoline with volume ratios of $20 \%, 50 \%$ and $85 \%$, known as $\mathrm{Bu} 20, \mathrm{Bu} 50$ and $\mathrm{Bu} 85$, respectively. The physical and chemical properties of test fuels are listed in Table 2.

Table 1. Engine specifications.

\begin{tabular}{ll}
\hline Items & Value \\
\hline Bore $(\mathrm{mm})$ & 75 \\
Stroke $(\mathrm{mm})$ & 84.8 \\
Displacement $(\mathrm{L})$ & 1.5 \\
Compression ratio & $10.5: 1$ \\
Rated power $(\mathrm{kW})$ & 78 \\
Maximum speed $(\mathrm{rpm})$ & 5000 \\
Maximum torque $(\mathrm{N} \cdot \mathrm{m})$ & 150 \\
\hline
\end{tabular}

Table 2. Physical and chemical properties of test fuels.

\begin{tabular}{lccccc}
\hline Items & G100 & Bu20 & Bu50 & Bu85 & Bu100 \\
\hline Density $\left(\mathrm{kg} / \mathrm{m}^{3}\right.$ at $\left.20^{\circ} \mathrm{C}\right)$ & 740.9 & 756.6 & 777.0 & 801.1 & 809.8 \\
Viscosity $\left(\mathrm{mm}^{2} / \mathrm{s}\right)$ & 0.530 & 0.707 & 1.275 & 2.710 & 3.632 \\
Octane number $(\mathrm{RON})$ & 94.9 & 95.2 & 99.7 & 120 & $>120$ \\
Sulfur $(\mathrm{mg} / \mathrm{kg})$ & 28 & 22 & 14 & 5 & 4.7 \\
Carbon $(\%)$ & 86.25 & 81.79 & 75.12 & 67.32 & 63.98 \\
Hydrogen $(\%)$ & 12.05 & 12.33 & 12.74 & 13.22 & 13.43 \\
Oxygen $(\%)$ & - & 6.3 & 12.0 & 18.7 & 21.5 \\
Low heat value(MJ/kg) & 42.8 & 39.5 & 34.6 & 28.9 & 26.5 \\
\hline
\end{tabular}

As can be seen in Table 2, the main properties of $n$ butanol basically meet the SI engine's requirements. Compared with G100, n-butanol blends get higher density, viscosity, octane number and oxygen content, but lower carbon content and low heat value (LHV). Especially, properties of bends with low n-butanol concentration (20\%) are close to those of gasoline. Moreover, the latent heat of vaporization at $25^{\circ} \mathrm{C}$ of gasoline is $380-500 \mathrm{~kJ} / \mathrm{kg}$, while that of n-butanol is $582 \mathrm{~kJ} / \mathrm{kg}$ [10].

\subsection{Experimental Method}

During this experiment, no modifications were made to the original engine and the ignition timing for different test fuels was kept the same. Firstly the maximum torque speed of test engine fuelled with G100 was found and that was $3000 \mathrm{rpm}$ with maximum torque up to $149.4 \mathrm{~N} \cdot \mathrm{m}$. Then with the engine keeping running at the speed of 3000rpm, the torque was controlled at $25 \%, 50 \%, 75 \%$ and $100 \%$ of $149.4 \mathrm{~N} \cdot \mathrm{m}$ (hereafter called $25 \%, 50 \%, 75 \%$ and $100 \%$ of full load), respectively. In order to make a fair comparison, the combustion characteristics of n-butanol blends, including $\mathrm{G} 100, \mathrm{Bu} 20, \mathrm{Bu} 50, \mathrm{Bu} 85$ and $\mathrm{Bu} 100$, were investigated under the above test conditions, respectively. But there was an exception for Bu100 that its maximum torque at $3000 \mathrm{rpm}$ was only able to reach $137.1 \mathrm{~N} \cdot \mathrm{m}$, which represented its full load test condition.

\section{Results and Discussion}

\subsection{The Cylinder Pressure and Pressure Rise Rate}

Measured by the combustion analyser, the $\mathrm{CP}$ is important to evaluate the combustion performance of fuels, which has been demonstrated in combustion heat release analysis of ethanol or n-butanol/diesel fuel blends by Rakopoulos et al. [11]. Figure 1 shows, under each test condition, the changes of the $\mathrm{CP}$ of test engine fuelled with G100, Bu20, Bu50, Bu85 and Bu100, respectively.

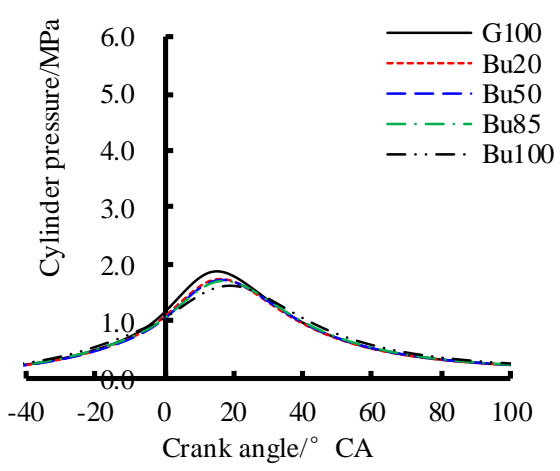

(a)

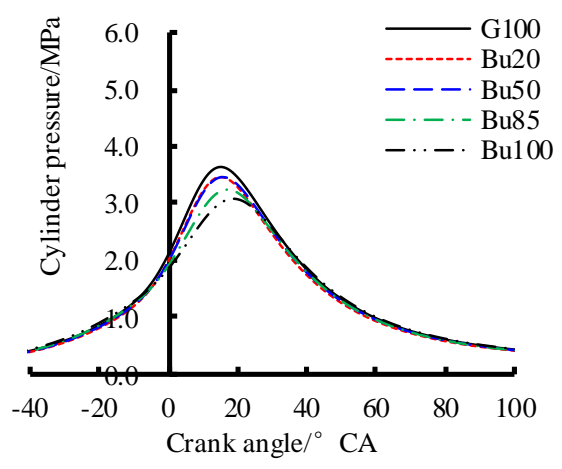

(b)

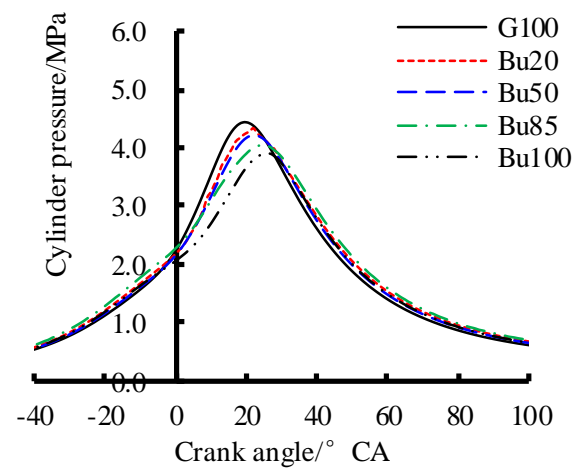

(c)

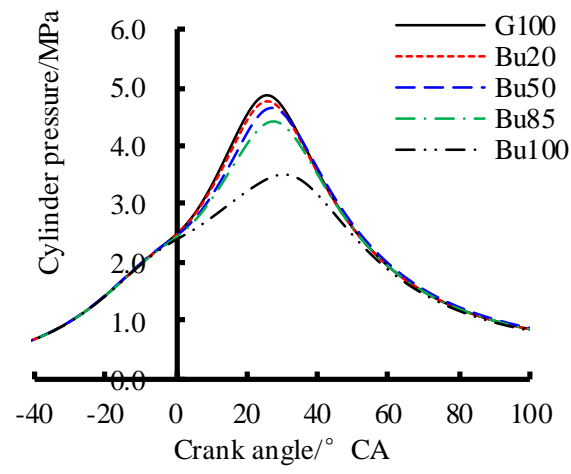

(d)

Figure 1. The CP of engine fuelled with n-butanol blends: a) $25 \%$ of full load, b) $50 \%$ of full load, c) $75 \%$ of full load, d) $100 \%$ of full load.

As is seen in Figure 1, peak value of CP increases with the increasing of the engine load. Throttle valve enlarges as 
the engine load increases, and thus the air-fuel mixture aspirated into the combustion chambers increases, then leading to the transferring speed of the flame across the chambers accelerating, which results in larger peak value of CP. Like CP, the peak value of PRR also increases with the engine load increasing. For the sake of concise, Figure 2 only shows the changes of PRR at $25 \%$ and $100 \%$ of full load.

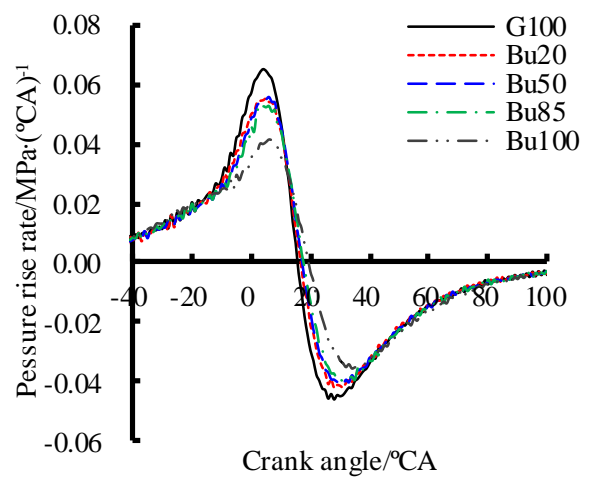

(a)

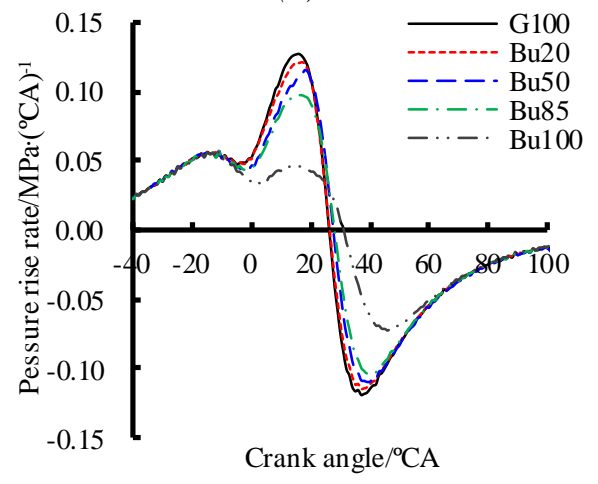

(b)

Figure 2. The PRR of engine fuelled with n-butanol blends: a) $25 \%$ of full load, b) $100 \%$ of full load.

From Figure 1 and Figure 2, we can also see that at the same engine load, the peak values of CP and PRR, along with the corresponding crank angles of peak values of $\mathrm{CP}$ and PRR increase with the blend ratio of n-butanol increasing. The LHV of n-butanol is relatively low, and thus the LHV of n-butanol blends becomes lower in comparison with that of gasoline, resulting in a decrease in the peak value of $\mathrm{CP}$; moreover, the addition of $\mathrm{n}$-butanol, whose latent heat of vaporization is higher than that of gasoline, induces a reduction in the temperature of cylinder, which further slows down the spreading speed of flame, and thereby the PRR decreases, together with the crank angles corresponded to peak values of CP and PRR increasing.

Figure 3 shows the effect of n-butanol ratio on the peak values of $\mathrm{CP}$ and PRR, and the corresponding crank angles of peak values CP and PRR at full load.

As are seen in Figure 3(a) and (b), the peak values of $\mathrm{CP}$ and PRR of test engine decrease with n-butanol content increasing. When the blend ratio of n-butanol is $20 \%$, the peak values of $\mathrm{CP}$ and PRR decrease within a narrow range $(\leq 4.8 \%)$; while the ratio is more than $20 \%$, the peak values of CP and PRR decrease to some extent. Specifically, the peak value of $\mathrm{CP}$ of the test engine fuelled with $\mathrm{Bu} 100$ declines by $28 \%$, while peak value of PRR declines by about $55 \%$ compared with those of G100.

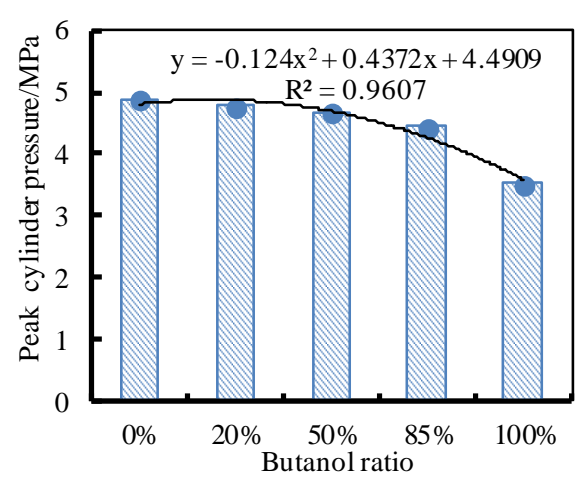

(a)

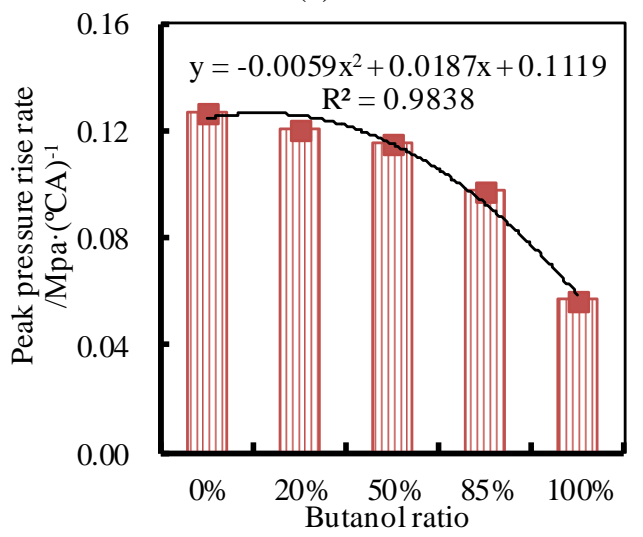

(b)

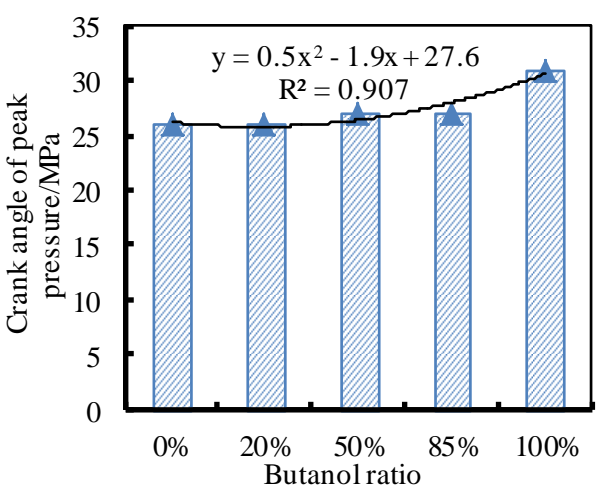

(c)

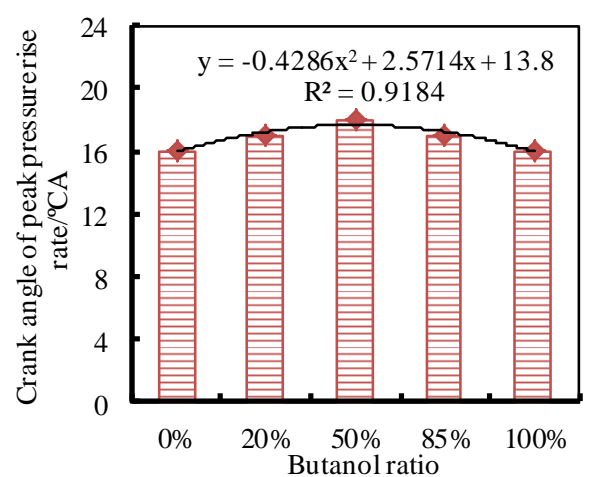

(d)

Figure 3. The effect of n-butanol ratio on the peak values of $C P, P R R$, and corresponding crank angles: a) peak value of $C P, b)$ peak value of $P R R, c)$ crank angle of peak value of $C P, d)$ crank angle of peak value of $P R R$.

On the one hand, since the LHV of n-butanol is lower than that of gasoline, the LHV of n-butanol blends decreases with the addition of n-butanol, which can engender a reduction in the peak value of $\mathrm{CP}$; whereas, nbutanol, as an oxygenated additive, is helpful for fuel 
burning. Thus for n-butanol blends with low n-butanol content, the LHV decreases a little while the oxygen contained in n-butanol blends improves combustion effectively, and as a consequence, the peak value of $\mathrm{CP}$ decreases slightly. However, as to n-butanol blends with high n-butanol content, the reduction in the LHV of fuel plays the leading role in combustion process, and for this reason, the peak values of $\mathrm{CP}$ and PRR decrease visibly.

As is seen in Figure 3(c), the crank angle corresponded to the peak value of $\mathrm{CP}$ increases as the blend ratio of $n$ butanol increases with the exception of that of Bu20. That is because that n-butanol contains oxygen, which helps burn fuel. However, the latent heat of vaporization of n-butanol is higher than that of gasoline, and vaporization of fuels could result in a reduction in temperature, which could further generate a decrease in the spreading speed of flame. Therefore, as for n-butanol blends with small n-butanol content (20\%), oxygen contained in n-butanol has the dominant influence, so the crank angle corresponded to the peak value of $\mathrm{CP}$ does not increase. On the contrary, as to n-butanol blends with large n-butanol content, the crank angle corresponded to the peak value of $\mathrm{CP}$ increases obviously $(\geq 4 \%)$ because the high latent heat of vaporization of n-butanol plays the leading role in combustion process. Eyidogan et al. [12] also obtained the same results in their research on performance and combustion characteristics of an SI engine fuelled with alcohol-gasoline blends.

As is seen in Figure 3(d), with the n-butanol concentration increasing, the crank angle corresponded to the peak value of PRR of engine fuelled with n-butanol blends increases firstly when the ratio is less than $50 \%$, and then decreases. This is attributed to synthetically functions of many factors, such as the LHV, oxygen content, and latent heat of vaporization of n-butanol blends.

\subsection{Rates of Heat Release}

Figure 4 shows the changes of IHRR and CFHR of test engine fuelled with G100, Bu20, Bu50, Bu85 and Bu100 at $25 \%$ and $100 \%$ of full engine load. The CFHR means the percentage of cumulative heat release to total heat release.

As is seen in Figure 4, at the same engine load, with the blend ratio of n-butanol increasing, the IHRR of blends reduces, and the crank angle corresponded to the peak value of IHRR increases; meanwhile, the total heat release decreases, and the crank angle corresponded to the total heat release decreases.

Figure 5 shows the effect of the n-butanol percentage in n-butanol blends on IHRR, the corresponding crank angle of the peak value of IHRR and total heat release at full load.

As is seen in Figure 5(a), an increase in the n-butanol percentage induces a reduction in the IHRR. When the blend ratio of n-butanol is less than $50 \%$, the IHRR of engine reduces in a small scale $(\leq 2 \%)$ compared with that of G100. However, when the ratio is over $50 \%$, the IHRR of engine reduces to a certain extent, and the higher the percentage of n-butanol is, the larger the reduction becomes. Specifically, the IHRR of engine fuelled with Bu100 reduces by $28 \%$ compared with that of G100.

As is seen in Figure 5(b), the higher the n-butanol percentage is, the larger the crank angle corresponded to the peak value of IHRR becomes. While engine burns nbutanol blends with n-butanol percentage equal to $20 \%$, the crank angle corresponded to the peak value of IHRR enlarges little $(0.5 \%)$ compared with that of G100. While n- butanol percentage is over $20 \%$, the crank angle corresponded to that enlarges more and more obviously as the n-butanol ratio increases. The crank angle corresponded to the peak value of IHRR of engine fuelled with Bu100 enlarges by $35 \%$ compared with that for G100.
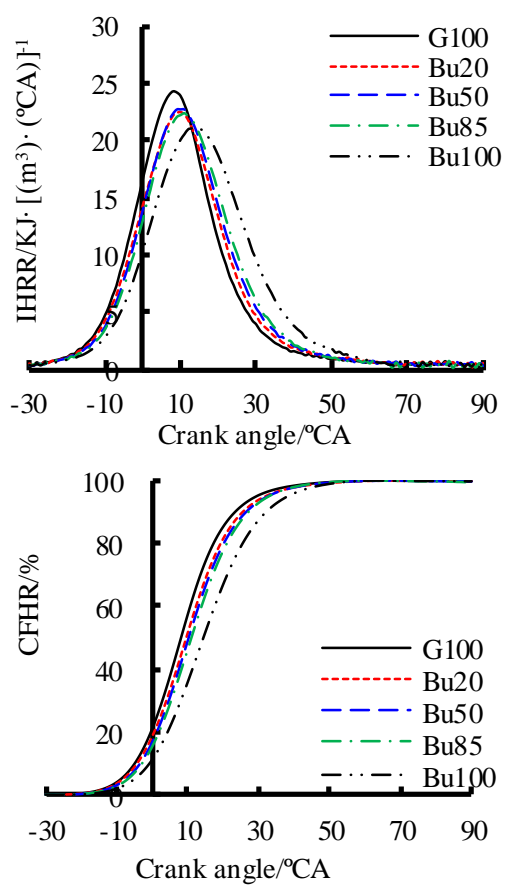

(a)
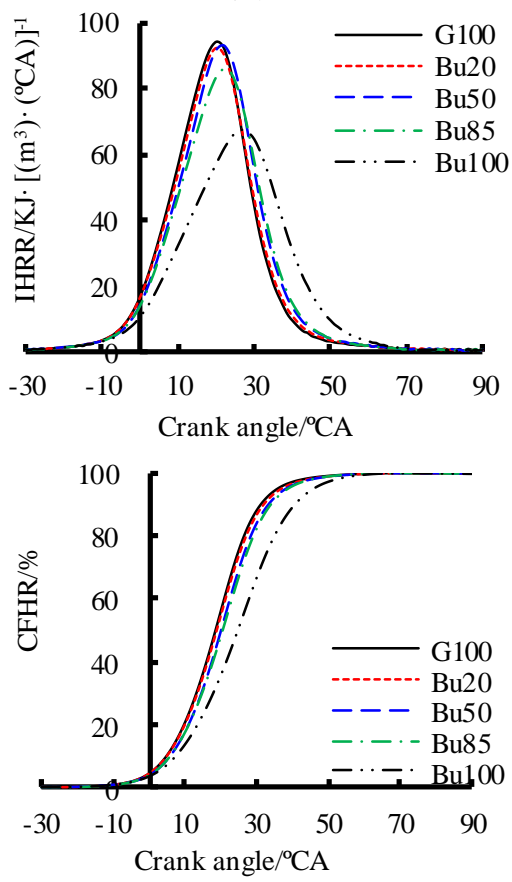

(b)

Figure 4. The instantaneous heat release rate (IHRR) and cumulative fraction of heat release (CFHR) of engine fuelled with n-butanol blends: a) $25 \%$ of full load, b) $100 \%$ of full load.

As is seen in Figure 5(c), the crank angle corresponded to the total heat release increases little and then decreases as the n-butanol content increases. Considering the low LHV of n-butanol, the heat release of n-butanol blends is thought to be smaller than that of G100 under the same test condition; in addition, the time from the spark plug arcing to formation of the flame centre lasts longer as a result of the high latent heat of vaporization of n-butanol, so the 
peak IHRR and total heat release of n-butanol blends reduce, and the crank angle corresponded to the peak IHRR of n-butanol blends enlarges. Meanwhile, the burning speed of n-butanol is higher than that of gasoline, which has been demonstrated by Szwaja and Naber [13] in a combustion study of n-butanol in a SI engine. With the addition of the fact that the ignition delay of n-butanol is larger than that of gasoline, so the corresponding crank angle of total heat release increases little and then decreases.

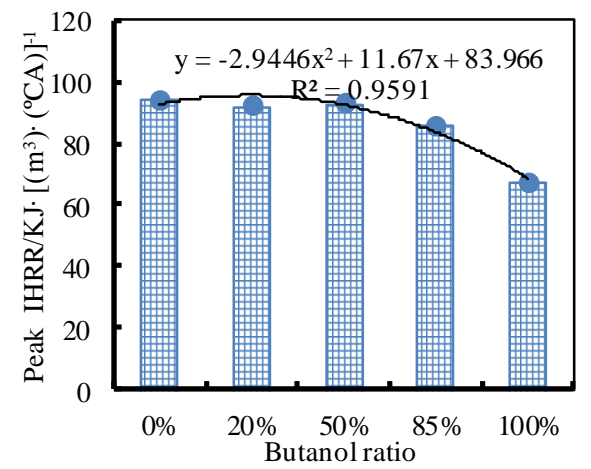

(a)

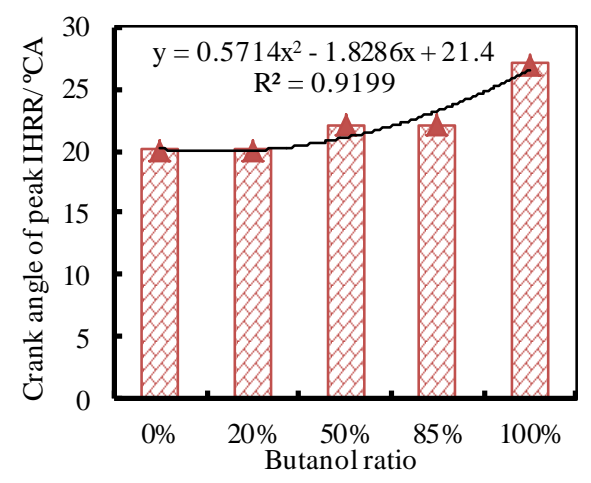

(b)

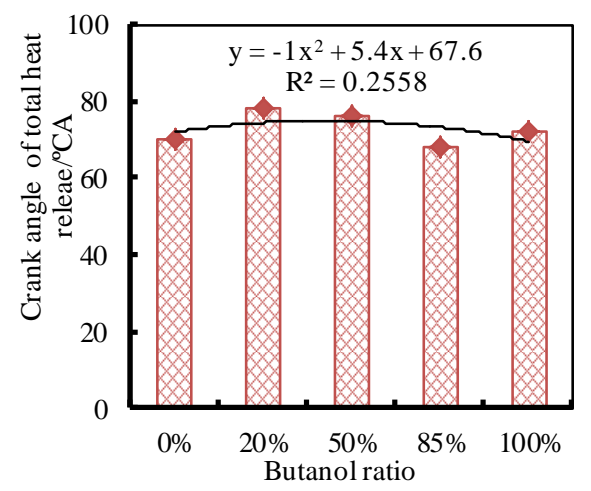

(c)

Figure 5. The effect of the n-butanol percentage on instantaneous heat release rate (IHRR), the corresponding crank angles of the peak IHRR and total heat release: a) peak value of IHRR, b) crank angle of peak IHRR, c) crank angle of total heat release.

The thermal efficiencies of five test fuels when test engine is working at $25 \%$ and $100 \%$ of full engine load are listed in Table 3. The thermal efficiency at $100 \%$ of full load is larger than that of $25 \%$ of full load. At the same engine load, with the n-butanol content in the n-butanol blends increasing, the thermal efficiency becomes larger. For example, the thermal efficiency of Bu100 is 1.2 times larger than that of G100 at $100 \%$ of full engine load. This shows that the addition of n-butanol can help to improve the thermal efficiency.

Table 3. Thermal efficiencies of test fuels.

\begin{tabular}{lrrrrc}
\hline Items & G100 & Bu20 & Bu50 & Bu85 & Bu100 \\
\hline $20 \%$ load & $28.9 \%$ & $29.6 \%$ & $32.2 \%$ & $35.8 \%$ & $38.1 \%$ \\
$100 \%$ load & $32.8 \%$ & $33.5 \%$ & $35.9 \%$ & $39.7 \%$ & $40.7 \%$ \\
\hline
\end{tabular}

\subsection{Cyclic Irregularity of Engine Fuelled with n-Butanol Blends}

In the book "Advanced fundamentals of internal combustion engine", Zhou [14] defined cyclic irregularity of engine as the variation of the combustion process between cycles when the engine is burning the same fuel and operating stably at one working condition (e.g. the same speed and the same torque). Cyclic irregularity can be specifically reflected through the fluctuations of some key combustion characteristics such as cylinder pressure, flame propagation, engine power output, etc. Li et al. [15], who had studied cyclic irregularity of combustion in a SI engine, showed that the influences of the cyclic irregularity of combustion on the performance of engine cannot be neglected; a reduction in cyclic variation can improve engine performance, fuel economy, and even reduce the harmful emissions. So it's of great importance to study the cyclic irregularity of each test fuel. Coefficients of variation of characteristic parameters $\left(\mathrm{COV}_{\mathrm{X}}\right)$ are used to show the cyclic irregularity, and can be defined as

$\operatorname{COV}_{X}=\frac{S D(X)}{\bar{X}} \times 100 \%$

In Eq. (1), $X$ is the characteristic parameter; $\operatorname{COV}_{X}$ is the coefficient of variation of parameter $X ; \bar{X}$ is the average of parameter $X ; \operatorname{SD}(X)$ is the sample standard deviation of parameter $X$, and can be defined as

$S D(X)=\sqrt{\frac{1}{\mathrm{~N}-1}[X(\mathrm{i})-\bar{X}]^{2}}$

In Eq. (2), $N$ is the sample number of parameter $X$, namely the number of cycles gained during the experiment; $\mathrm{X}$ (i) is the parameter gained in the $i$ th engine cycle.

During this experiment, for each test fuel, 100 engine cycles have been gained in succession under each test condition, which means that the sample number of every characteristic parameter is 100 . Then, the coefficients of variation of combustion characteristic parameters such as the peak values of $\mathrm{CP}$ and IHRR, along with the corresponding crank angles of peak $\mathrm{CP}$ and peak IHRR can be calculated by Eq. (1).

When the test engine is kept running at the speed of 3000rpm, the coefficients of variation of the above combustion parameters for each test fuel at each load are shown in Figure 6.

As is seen in Figure 6, with the engine load increasing, the coefficients of variation of the peak values of CP, IHRR and their corresponding crank angles reduce. What's more, $\mathrm{COV}_{\mathrm{X}}$ increases as the n-butanol blend ratio increases. 


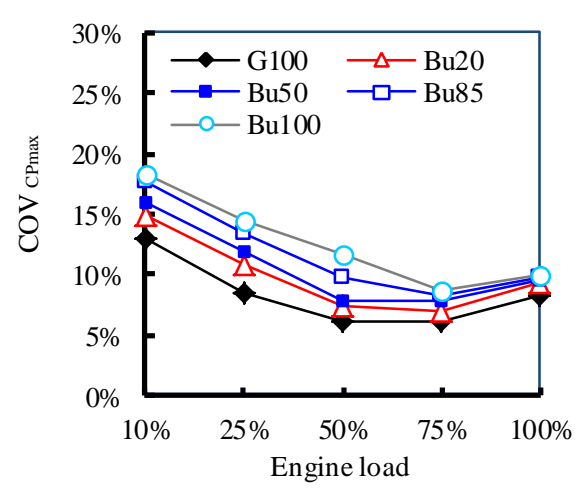

(a)

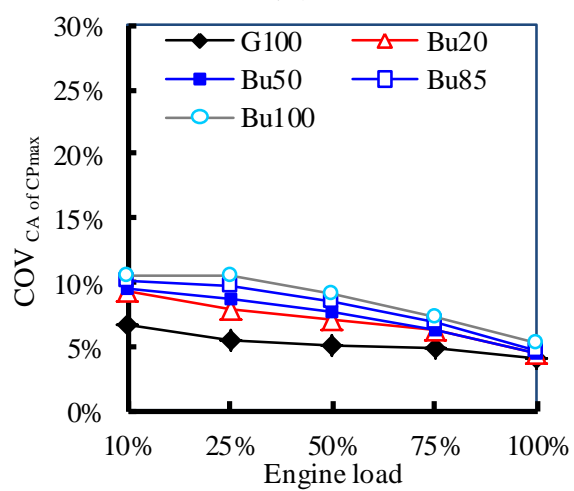

(b)

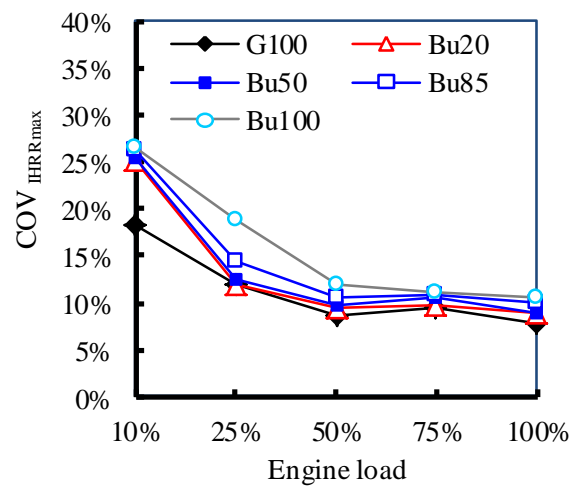

(c)

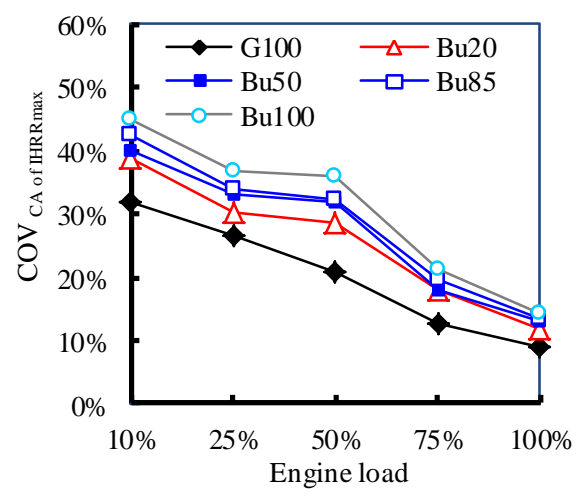

(d)

Figure 6. The cyclic irregularity of engine fueled with $n$ butanol blends: a) peak value of $C P, b)$ crank angle $(C A)$ of peak value of $C P, c)$ peak value of IHRR, d) crank angle (CA) of peak value of IHRR

This is because that the peak value of CP (PRR) depends heavily on the amount of energy contained by the air-fuel mixture that formed during the ignition delay period, as Ceviz and Yüksel [16] explained in their study on effects of ethanol-unleaded gasoline blends on cyclic variability in a SI engine. Considering the high latent heat of vaporization of n-butanol, the larger the n-butanol percentage is, the longer the time from spark plug arcing to formation of the flame centre lasts, so the $\mathrm{COV}_{\mathrm{X}}$ increases with the n-butanol ratio increasing. At light engine load, as the quantity and temperature of air-fuel gas in the combustion chamber are low, the ignition delay period is prolonged, resulting in an increase in $\mathrm{COV}_{\mathrm{X}}$. Then as the engine load enlarges, temperature of the chamber rises, and fuel burning speeds up, leading to the decrease of $\mathrm{COV}_{\mathrm{X}}$. This is consistent with the result achieved by Rakopoulos et al. [17] in their study on the cyclic variability of nbutanol/diesel fuel blends in a DI diesel engine.

\section{Conclusions}

1) With increasing of n-butanol blend ratio, the peak values of $\mathrm{CP}$ and PRR of engine decrease, whereas the corresponding crank angles increase. When the n-butanol ratio is no more than $20 \%$, the peak value of $\mathrm{CP}$ and PRR change are within a narrow range.

2) With increasing of n-butanol blend ratio, the peak values of IHRR and total heat release decrease, and the corresponding crank angle of the peak value of IHRR increases while the corresponding crank angle of total heat release decreases. When the n-butanol ratio is no more than $20 \%$, the peak values of IHRR and total heat release decrease little.

3) With increasing of n-butanol blend ratio, the coefficients of variation of the peak values of CP, IHRR, and their corresponding crank angles increase.

4) The combustion of the EFI gasoline engine becomes mild when fuelled with n-butanol blends, which further gives the benefit of reducing $\mathrm{NO}_{\mathrm{X}}$ emissions of the engine. However, the ignition advanced angle of the engine should be enlarged to avoid power decreasing of $n$-butanol blends.

\author{
Nomenclature \\ $\mathrm{CP} \quad$ cylinder pressure, $\mathrm{MPa}$ \\ PRR pressure rise rate, $\mathrm{MPa} /\left({ }^{\circ} \mathrm{CA}\right)$ \\ IHRR instantaneous heat release rate, $\mathrm{KJ} /\left[\mathrm{m}^{3} \bullet\left({ }^{\circ} \mathrm{CA}\right)\right]$ \\ CFHR cumulative fraction of heat release, $\%$ \\ LHV low heat value, $\mathrm{MJ} / \mathrm{kg}$
}

\section{References}

[1] D. C. Rakopoulos, C. D. Rakopoulos, D. T. Hountalas, E. C. Kakaras, E. C. Giakoumis, R. G. Papagiannakis, Investigation of the performance and emissions of bus engine operating on butanol/diesel fuel blends, Fuel, 89 , 2781-2790, 2010.

[2] X. J. Zeng, J. Deng, H. Kong, L. Lu, C. J. Cai, Research progress of butanol as an alternative vehicle fuel, Small Internal Combustion Engine and Motorcycle, 41, 76-80, 2012.

[3] B. R. Wigg, A study on the emissions of butanol using a spark ignition engine and their reduction using electrostatically assisted injection (dissertation), Urbana, USA, University of Illinois at Urbana-Champaign, 2011.

[4] J. Serras-Pereira, P. G. Aleiferis, D. Richardson, S. Wallace, Characteristics of ethanol, butanol, iso-octane and gasoline sprays and combustion from a multi-hole injector in a DISI Engine, SAE International Journal of Fuels and Lubricants, 1, 893-909, 2009.

[5] S. S. Merola, C. Tornatore, G. Valentino, L. Marchitto, F. Corcione, Optical investigation of the effect on the 
combustion process of butanol-gasoline blend in a PFI SI boosted engine, SAE Paper, 2011-24-0057, 2011.

[6] J. Yang, K. Li, X. L. Yang, J. P. Liu, Z. H. Zhong, A study on the heat release law of butanol-gasoline blends in combustion, Automotive Engineering, 31, 911-914, 2009.

[7] K. Li, B. L. Wang, Z. Y. Han, J. P. Liu, Z. H. Zhong, An experimental study on the feasibility of using butanol-gasoline blends fuels in gasoline engine, Automotive Engineering, 31, 820-823, 2009.

[8] J. Dernotte, C. Mounaim-Rousselle, F. Halter, P. Seers, Evaluation of butanol-gasoline blends in a port fuelinjection, spark-ignition engine, Gas Sci Technol-Rev, 65, 345-351, 2010.

[9] T. Wallner, S. A. Miers, S. McConnell, A comparison of ethanol and butanol as oxygenates using a directinjection, spark-ignition engine, Journal of Engineering for Gas Turbines and Power, 131, 032802, 2009.

[10] C. Jin, M. F. Yao, H. F. Liu, C. F. Lee, J. Ji, Progress in the production and application of n-butanol as a biofuel, Renewable and Sustainable Energy Reviews, 15, 4080-4106, 2011.

[11] D. C. Rakopoulos, C. D. Rakopoulos, R. G. Papagiannakis, D. C. Kyritsis, Combustion heat release analysis of ethanol or n-butanol diesel fuel blends in heavy-duty DI diesel engine, Fuel, 90, 1855-1867, 2011.

[12] M. Eyidogan, A. N. Ozsezen, M. Canakci, A. Turkcan, Impact of alcohol-gasoline fuel blends on the performance and combustion characteristics of an SI engine, Fuel, 89, 2713-2720, 2010.

[13] S. Szwaja, J. D. Naber, Combustion of n-butanol in a spark-ignition IC engine, Fuel, 89, 1573-1582, 2010.

[14] L. B. Zhou, Advanced fundamentals of internal combustion engine. Beijing: China Machine Press, 2005.

[15] X. H. Li, D. M. Jiang, H. X Shen, Study on evaluated methods of pressure cyclic variation in spark ignition engines, Transactions of CSICE, 18, 171-174, 2000.

[16] M. A. Ceviz, F. Yüksel, Effects of ethanol-unleaded gasoline blends on cyclic variability and emissions in an SI engine, Applied Thermal Engineering, 25, 917-925, 2005.

[17] C. D. Rakopoulos, D. C. Rakopoulos, E. G. Giakoumis, D. C. Kyritsis, The combustion of nbutanol/diesel fuel blends and its cyclic variability in a direct injection diesel engine, Journal of Power and Energy, 225, 289-308, 2011. 